Rapid Reviews COVID-19

\title{
Reviews of "Scent dog identification of SARS- CoV-2 infections, similar across different body fluids"
}

\author{
Albertini Mariangela ${ }^{1}$, Patrizia Piotti $^{\mathbf{2}}$, Catherine Reeve $^{\mathbf{3}}$ \\ ${ }^{1}$ Associated Professor, University of Milan: Universita degli Studi di Milano, Department of \\ Veterinary Medicine, Italy, \\ 2Department of Veterinary Medicine, University of Milan, Italy, \\ ${ }^{3}$ Lecturer, Queen's University Belfast, Psychology, United Kingdom
}

Published on: Apr 09, 2021

DOI: $10.1162 / 2 \mathrm{e} 3983 f 5 . c 24 b 75 d 4$

License: Creative Commons Attribution 4.0 International License (CC-BY 4.0). 
To read the original manuscript, click the link above.

Summary of Reviews: Reviewers find great potential in this preprint on the use of scent dogs to identify SARS-CoV2 infections, however they raise a number of concerns about the clarity and conditions of the experimental methods used.

Reviewer 1 (Albertini Mariangela, Patrizia Piotti)

Reviewer 2 (Catherine Reeve) | प्र००

\section{RR:C19 Strength of Evidence Scale Key}

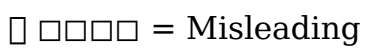

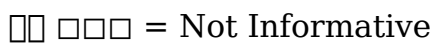

प्रा पि = Potentially Informative

प्राप्र = Reliable

प्राप्र = Strong

To read the reviews, click the links below. 